\title{
Saúde e Direito à Informação
}

\author{
Rita de Cassia Barradas Barata *
}

Este artigo discute o papel da grande imprensa na divulgação de informaçôes de saúde, no contexto de fatos coletivos, como as epidemias.

Através de matérias e notícias divulgadas pela imprensa paulista, no periodo de janeiro de 88 a julho de 89, é possivel identificar comportamentos das autoridades sanitárias, bem como o comportamento da grande imprensa.

$O$ direito à informação é considerado, na perspectiva da construção de uma consciência sanitária crítica, que permita aos grupos sociais agirem diante de situações de ameaça potencial à saúde.

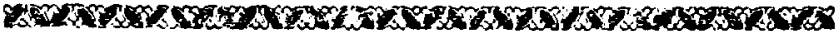

Os meios de comunicação de massa, entre eles a grande imprensa, se constituem em importantes veiculos na divulgação de informaçōes de saúde para parcelas significativas da populaçăo.

Os aparelhos ideológicos de Estado funcionam predominantemente pela ideologia e, a seu modo, concorrem para a reprodução das relações capitalistas (1). Esta característica estrutural marca contraditoriamente a atuação da imprensa enquanto veículo de divulgação e, simultaneamente, instrumento de formação de opinião, para algumas camadas sociais, fundamentalmente.

Através da ideologia, as massas humanas se organizam, se movem, adquirem consciência de sua posição (8). Daí a grande importância das instâncias sociais mais diretamente relacionadas ao exercício da ideologia, tais como os meios de comunicação.

$\mathrm{Na}$ área da saúde, o papel preponderante dos meios de comunicação irá se revelar nas situaçōes coletivas, como as epidemias, quando a população se vê indistintamente ameaçada, isto é, a importância da imprensa, enquanto canal de informação/reivindicação, é mediatizada pelo caráter mais ou menos coletivo do agravo em questão, bem como pelo potencial de difusão social do problema, de modo a "borrar" os limites de classe.

Cademos de Saáde Páblica, RJ, 6 (4): 385-399, out/dez, 1990
* Professora Assistente do Departamento de Medictna Social da Faculdade de Ciências Médicas da Santa Casa de Sáo Paulo. 
* Jornais: O Estado de São Paulo, Jormal da Tarde, Folha de Sào Paulo, Folha da Tarde, Noticias Populares e Diário Popular.
Para exemplificar a afirmação feita acima, podemos citar o comportamento da imprensa diante das epidemias de meningite meningocócica, ocorridas na década de $70 \mathrm{e}$, mais recentemente, a partir de 1986-87, e a epidemia de sarampo de 1984, em São Paulo (2).

No caso das epidemias de doença meningocócica, a imprensa deu ampla cobertura, a despeito inclusive da censura em vigor nos anos 70 , enquanto a epidemia de sarampo mereceu pouca atenção. Em ambas as circunstâncias, tratava-se de eventos coletivos e que, portanto, a priori deveriam interessar a toda população. Entretanto, enquanto a doença meningocócica, em sua forma epidêmica, ameaça a todos os estratos sociais, embora em grau e intensidade diferentes, o sarampo só representa uma ameaça real para aqueles segmentos sociais mais pobres e desassistidos, onde a desnutrição e a falta de acesso à vacinação se constituem em importantes fatores de risco.

O fato de determinadas camadas da população não se constituírem em "formadores de opinião", isto É, não disporem de "voz" na cena política, torna seus problemas desinteressantes para os órgãos de comunicação, a não ser naquilo que eles possam ter de "folclórico", insólito ou sensacionalista, merecendo, aí, espaço, em determinados veículos destinados a uma certa faixa de público.

A cobertura dada pela imprensa a eventos coletivos, tais como epidemias, traz, em geral, uma dupla mensagem: reflete, de um lado, a atuação do Estado diante desses eventos, ou o comportamento da sociedade civil, e, de outro, a própria atuaçāo da imprensa enquanto órgão de divulgação/formaçăo de opiniāo.

A partir da temática proposta, saúde e direito à informaçāo, optamos por enfocar as diversas atitudes do Estado diante da epidemia de doença meningocócica e, também, o comportamento da imprensa em seu trabalho de divulgação.

O material disponivel para essa análise é o conjunto de matérias jornalísticas divulgadas pela imprensa $\left.{ }^{*}\right)$. Não pretendemos realizar um estudo exaustivo dos meios de comunicação, confrontando clientelas, linhas editoriais, compromissos etc. Limitamo-nos a realizar uma análise de conteúdo das matérias divulgadas pela imprensa paulista, no período de janeiro de 1988 a julho de 1989. Através dessa análise, procuramos evidenciar algumas linhas de comportamento das autoridades de saúde, relacionando-as com diferentes concepçōes de atuaçāo do Estado, e, também, marcar alguns traços de comportamento da imprensa, no desempenho de sua tarefa informativa. Procuramos, ainda, demonstrar nossas afirmações, através de citações dos artigos em questão. 
Evidentemente, a atuaçāo, quer das autoridades sanitárias, quer dos jomalistas, năo é monolítica, isto é, não se faz sempre na mesma direção, mas, antes, é marcada por diversas nuanças e até mesmo contradições.

As concepções de Estado, subjacentes às diferentes posturas das autoridades sanitárias, podem ser agrupadas em duas grandes categorias: a concepção tecnocrática e a concepção democrática.

A concepção tecnocrática caracteriza-se, entre outras coisas, pela "naturalizaçāo" da realidade social; pela concentração de todo o conhecimento da elite governante; pelo exercício autoritário do poder, com exclusão da "sociedade política" e pela crença na benevolência intrínseca do poder tecnocrático (15).

Nas sociedades industriais modernas, o conhecimento de que a elite governante é detentora vem revestido ideologicamente do prestígio conferido à ciência e, portanto, se apresenta, a toda a sociedade, como intrinsecamente bom e politicamente neutro, estando, portanto, acima dos interesses de grupos particulares.

A concepção tecnocrática de atuação do Estado não é exclusiva de determinados regimes de governo, podendo estar presente em diferentes contextos políticos, muito embora seja mais freqüentemente encontrada em regimes autoritários $(3,4,5)$.

$\mathrm{Na}$ área da Saúde, particularmente no que diz respeito a epidemias, esta concepção se exprime através de posturas "técnicas", que consideram a população despreparada para receber a informação correta, uma vez que apenas os técnicos possuem formaçäo científica necessária à real compreensão do problema. Tal postura pode se traduzir pela afirmação explícita de que só aos técnicos interessa conhecer os dados relativos ao problema, ou por afirmaçōes que negam ou tendem a minimizar os problemas existentes (2).

A alegação maior, diante de tais comportamentos, tem sido sempre a preservação da tranqüilidade, supondo-se que o conhecimento inadequado dos fatos, motivados pela ignorância da populaçāo, conduziria ao pânico (2).

A postura tecnocrática se exprime, em sua pureza, nos regimes autoritários, valendo-se de recursos como a censura à imprensa, para evitar a divulgação de informaçōes que considera de propriedade dos técnicos.

$\mathrm{Na}$ situação atual da sociedade brasileira, a concepção tecnocrática sofre algumas distorçōes, sendo menos aceitável o argumento de que os dados só interessam aos técnicos. As posturas assumidas por algumas autoridades da área de saúde variam desde a simples e peremptória negação, passando por tentativas de confundir a população com pretensas "discussões técnicas", atế a aceitação da existência do problema, em uma perspectiva que visa reduzir sua importância. 
A concepção democrática do Estado se coloca em posição diametralmente oposta, assumindo, em geral, o direito que a populaçấo tem de ser informada corretamente sobre os problemas que a afligem. Mais do que simplesmente garantir a divulgação das informaçôes, os adeptos e praticantes de uma gestão democrática do Estado advogam o acesso da população a informações corretas e completas, não-mistificadoras da realidade e da ação dos govemantes.

$\mathrm{Na}$ atual epidemia de meningite meningocócica, é possivel identificar ambas as posições por parte das autoridades sanitárias; alguns preferem negar o problema, alegando que a população reage emocionalmente à informação da existência de uma epidemia, não conseguindo aquilatar seu real significado; enquanto outros afirmam a existência do problema e procuram, de diferentes maneiras, conscientizar a população.

Em São Paulo, onde dispomos das informações epidemiológicas e, também, das matérias jornalísticas, a atuação dos responsáveis pela vigilância epidemiológica foi, até certo ponto, ambígua: quando o assunto surgiu na imprensa, as autoridades afirmaram a existência da epidemia, embora não tivessem vindo a público dizer da existência dela, desde o seu começo.

Durante o ano de 1987, vários meses apresentaram incidências epidêmicas para doença meningocócica, na região Metropolitana. No ano de 1988, apenas o mês de fevereiro não apresentou comportamento epidêmico.

Somente em julho, a imprensa começou a noticiar a existência de uma possível epidemia em São Paulo. No dia 6 de julho, vários jornais divulgaram as informaçöes do Dr. Alexandre Vranjac, diretor do Centro de Vigilância Epidemiológica (CVE), dando conta de que a incidência da doença havia ultrapassado os limites de normalidade, definidos com base no comportamento da doença no período de 1979 a 1985 (9).

Dois dias depois, uma técnica do Ministério da Saúde nega a existência de epidemia no país, afirmando que o aumento do número de casos de meningite meningocócica em nove estados brasileiros caracteriza um pré-surto da doença e acrescenta que o pré-surto é caracterizado pelo aumento do número de casos da doença em épocas frias (11).

No dia seguinte, é a vez do Ministro da Saúde, Dr. Borges da Silveira, afirmar que os números referentes à ocorrência de meningite no Brasil não é surto nem preocupam, apesar de o ministério estar atento (10).

A posição dos técnicos do Ministério da Saúde, e do próprio ministro, só pode ser entendida dentro de duas perspectivas: ou bem o ministro está traba- 
lhando com as unidades da federação como um todo, sendo, assim, incapaz de detectar epidemias, a não ser que elas atinjam o estado todo, ou o ministro prefere ocultar a existência delas.

Diante das declaraçōes das autoridades de âmbito federal, o Centro de Vigilância Epidemiológica de São Paulo volta a enfatizar que a situação é epidêmica. Tal informaçāo é corroborada pela apresentação de dados, mostrando um aumento do número de casos da ordem de $24 \%$ em relação ao primeiro semestre de 1987 (8).

Frente ao posicionamento do órgão de vigilância de São Paulo, o Ministério da Saúde reconheceu o surto de meningite meningocócica do tipo B na Gran= de São Paulo e em Santa Catarina (18). Entretanto, tal reconhecimento veio acompanhado de uma tentativa de escamoteamento da situaçāo, num jogo de palavras/conceitos entre surto e epidemia, conferindo a esses termos significados diferentes daqueles que eles normalmente têm entre os epidemiologistas.

Essas estatisticas podem definir um surto de meningite tipo $B$, mas nâo se pode afirmar que haja uma epidemia. $O$ que há é um sinal de alerta.

$\mathrm{Na}$ mesma matéria, é possível constatar um outro recurso freqüentemente usado pelas autoridades sanitárias. O Secretário Estadual de São Paulo confirma a existência da epidemia e aduz que ela está sob controle, devendo diminuir nas próximas semanas, em decorrência do trabalho de profilaxia realizado pela Secretaria.

Parece ser irresistível para os técnicos e políticos fazer "previsōes" relativas ao curso da epidemia. No mais das vezes, tais "previsōes" não se confirmam, haja vista que, geralmente, se baseiam mais no desejo do que em dados concretos. Cada epidemia, embora possa guardar características comuns com outros processos epidêmicos, traz em si uma certa dose de novidade, visto que a estrutura epidemiológica, isto é, as condiçōes concretas que a geraram, está em permanente transformação.

Adotando uma postura até então inédita, o governo de São Paulo publicou nos jornais matéria paga, alertando a população para a existência da epidemia, assinalando que as proporções da mesma ainda eram pequenas e divulgando os sinais e sintomas mais freqüentes (21).

Cerca de uma semana depois, novo comunicado é publicado, desta vez endereçado aos pais e professores, alertando e esclarecendo os mesmos quanto à situação da doença. Além disso, a assessoria de imprensa passou a divulgar, semanalmente, o número de casos 
e óbitos, bem como os valores acumulados mensais, para todos os jornais, rádios e televisōes.

A atitude do ministro se manteve a mesma. Em agosto, o ministro Borges da Silveira afirmava:

Como São Paulo não tem uma epidemia, a vaci. nação não será de massa e sim de bloqueio. Isto significa que será aplicada na rua de maior incidência, nos vizinhos e principalmente nas crianças da redondeza (23).

Nos meses seguintes, com a redução no número de casos, em função da variação sazonal da doença, o número de artigos veiculados pela imprensa também diminuiu.

A meningite voltou a ser assunto no final de abril, quando, novamente, os casos aumentaram, acompanhando a variação sazonal habitual.

Em matéria de 28 de abril, o Diário Popular (17) informa a existência de uma nova epidemia, cujo início ocorrera em fevereiro. Na prática, apenas o mês de janeiro apresentou ocorrência normal, podendo-se, portanto, considerar que se tratava da mesma epidemia, presente desde 1987.

Com a mudança do Ministro da Saúde e de alguns técnicos do ministério, a atitude das autoridades de âmbito federal mudou radicalmente:

Além da Grande São Paulo o ministro adverte que há epidemia de meningite em Macapá, Fortaleza, Natal, Recife, Teresina, Aracaju, Salvador, Vitória, Rio de Janeiro, Porto Alegre, Manaus, Florianópolis, Joinville e Blumenau (27).

No dia seguinte à divulgação dessas informaçōes pelo ministério, quatro das secretarias dos 13 estados mencionados negaram a existência do problema.

Diante clo crescimento, contínuo, embora gradual, da epidemia en São Paulo, a questão da compra de vacinas antime ringocócica $B$, produzidas em Cuba, passou para pri ieiro plano.

Com relação à aquisição de vacinas, surgiram vários problemas, disputas políticas e pouquíssima informaçẫo adequada para a população. $\mathrm{O}$ maior problema está na limitada capacidade produtiva do Instituto encarregado da comercialização das vacinas. Além dessa dificuldade, havia o preço considerado excessivo (cerca de US\$ 10.00 a dose) e o pouco conhecimento sobre a sua eficácia.

Já no final de junho, as autoridades de saúde de São Paulo anunciaram a intenção de vender as vacinas. Segundo o Governador Orestes Quércia:

Temos de dar essa chance para as pessoas que podem comprar (28).

Sucessivas declaraçöes do presidente da FURP (Fundaçāo para o Remédio Popular) e do secretário de saúde alegavam que a venda se destinava a arrecadar 
recursos para a compra de mais vacinas, que seriam distribuídas gratuitamente. Entretanto, a questão da limitação de doses disponíveis estava condicionada pela própria capacidade produtiva do laboratório cubano, e não apenas pelo custo.

A reação da sociedade civil foi suficiente para que a venda fosse suspensa. Aliada a esta reação, a manifestação do Conselho Nacional de Saúde, desaconselhando tal prática, foi decisiva.

As questōes tratadas até aqui demonstram, em parte, as atitudes tomadas pelas autoridades sanitárias diante de questões de interesse coletivo. Durante a fase da ditadura militar, os conflitos entre poderes ou não existiam ou eram escamoteados. Atualmente, a imprensa pode cobrir livremente os conflitos surgidos na condução dessas questôes, permitindo à população 0 acesso às informaçốes.

Além do benefício imediato a nível dos direitos da cidadania, o acesso às informaçōes traz para a população outros dividendos.

$\mathrm{O}$ fato de se divulgar a existência de uma epidemia leva a população e os médicos a se mostrarem atentos para o problema, ocorrendo, então, busca de atendimento e diagnóstico mais precoces. A rápida aplicação da terapêutica correta reduz a letalidade, bem como os risços de complicações e seqüelas.

E nas questōes de âmbito coletivo que o dever do Estado de informar a coletividade sobre o que está ocorrendo se coloca, uma vez que a vivência pessoal da doença não permite aos indivíduos captar a dimensão do problema.

Mais do que a simples divulgação da existência de epidemia e do número de casos e óbitos ocorridos, compete ao Estado informar às pessoas sobre o comportamento da doença, não apenas do ponto de vista clínico (sinais e sintomas), mas, principalmente, em seus aspectos epidemiológicos: grupos de riscos, distribuição geográfica, fatores que favorecem a transmissão etc.

Embora os trechos extraídos das matérias jornalísticas permitam identificar conjuntos de posturas diferentes quanto ao direito à informação, nāo há, ainda, por parte das autoridades, a prática salutar de usar os meios de comunicação de massa para aumentar a consciência sanitária da população. As informações divulgadas são, em geral, parciais, incompletas e limitadas.

Passamos, agora, a analisar o comportamento da imprensa diante da situação epidêmica.

Inicialmente, podemos distinguir, dentre a totalidade de matérias divulgadas, a escassez relativa de matérias assinadas, quer por jornalistas, quer por técnicos da área de saúde. Geralmente, tais matérias são 
resenhas, contendo informaçōes gerais sobre a doença, referindo-se ou não à situação concreta em questão.

Um outro conjunto de matérias, numericamente bastante expressivo, contém as informações e quadros sinópticos divulgados pelos órgāos de vigilância epidemiológica. Mais ou menos na mesma linha, aparecem artigos, contendo informaçōes gerais, principalmente clínicas, elaboradas pela redação. É comum, principalmente em alguns jornais, recorrer-se a opiniōes de especialistas estrangeiros. Tal prática é, às vezes, perigosa, uma vez que tais especialistas desconhecem a situaçāo epidemiológica local, emitindo opiniōes válidas em seus países porém inaplicáveis em um outro contexto. O recurso à autoridade de profissionais de outros países pode, até certo ponto, refletir a "desconfiança" frente às informações oficiais, ou o reconhecimento de uma maior competência desses profissionais.

Evidentemente, há exceções, e um exemplo disso pode ser encontrado na matéria Há vacinas nos Estados Unidos. Mas não servem para o Brasil, divulgada pelo Jornal da Tarde, em 06/08/88 (22).

Diante das escassas informaçōes disponíveis sobre as vacinas produzidas em Cuba, o jomal conversou com o Dr. Carl Frafch, do F. D. A (Food Drug Administration), que havia participado dos trabalhos de elaboração da vacina.

Manter o interesse dos leitores em um assunto que raramente apresenta lances interessantes, nem sempre é uma tarefa fácil. Alguns jornais, mesmo aqueles mais conceituados, recorrem à divulgação de fatos insólitos, folclóricos ou até mesmo sensacionalistas. A seguir, formecemos alguns exemplos:

O Delegado Antonio Freitas anunciou que vai interditar a Igreja Pentecostal Deus é amor, porque seu pastor, Donozor do Prado, permitiu que o corpo de Dione Fernandes Benevides, que morreu de meningite, ficasse exposto no templo, por muito tempo'o que pode ter provocado a contaminaçāo de centenas de pessoas que passam por ali diariamente... (20).

Além do insólito do caso, tal notícia desinforma, na medida em que faz acreditar na possibilidade de contaminação ambiental a partir de um cadáver, o que está absolutamente incorreto.

O Projeto Saci do governo do Espirito Santo está recomendando o uso de patuás como método preventivo contra o surto de meningite $B$. Desde quinta-feira, quem liga para o número $148 \mathrm{em}$ Vitória ouve uma voz que aconselha a colocaçāo no peito de uma pedra de cânfora, um dente de alho e quatro gräos de pimenta do reino. O secretário da saúde condena a prática: a Secretaria nunca orientou isso, pois não é macumbeira (29). 
Em função dos muitos anos de arbítrio e censura, os jornalistas tendem a desconfiar das informaçōes fornecidas pelas autoridades e, muitas vezes, tentam buscar mecanismos de "checagem" dos dados, que só aumentam a confusão. Um exemplo disso pode ser dado pelo episódio, envolvendo o Centro de Vigilância Epidemiológica e o Serviço Funerário da Capital:

Apesar do diretor do SVE afirmar que irá divulgar o que está acontecendo, seus dados estão baseados somente em pacientes internados no Hospital Emílio Ribas, e as estatísticas poderão ficar bastante distantes da realidade. Prova disso são os 53 óbitos causados pela doença, conforme registra o Serviço Funerário no mês de junho... Pelos dados da Secretaria da Saúde, foram notificados, desde janeiro, 225 casos da doença com 25 óbitos... (17).

O que o jornalista não sabe é que o fato de meningite aparecer como causa de óbito no atestado não significa, necessariamente, tratar-se de um óbito por meningite meningocócica $\mathrm{B}$, uma vez que há inúmeros outros agentes etiológicos de meningite, inclusive produzindo letalidades mais altas do que os meningococos, e outras causas não-infecciosas de meningite. Mas o importante a ressaltar é a atitude de desconfiança, fundamentada, certamente, na experiência de muitos anos em que as autoridades, sistematicamente, ocultaram as informaçōes à imprensa.

Por outro lado, o interesse que os jomalistas sempre demonstram com relação aos óbitos sugere que, no imaginário, a epidemia vem comumente associada a idéias de excesso de mortes, o que, entretanto, vai se verificar apenas em situaçōes particulares, principalmente hoje, quando os recursos terapêuticos disponíveis são razoavelmente eficazes.

Finalmente, com respeito ao direito à informação, julgamos importante ressaltar que este direito pressupõe, mais do que simplesmente a divulgação de alguns fatos, aspectos relativos à qualidade das informações divulgadas.

Considerar a informação e o acesso a ela no âmbito dos direitos de cidadania pressupõe atribuir ao conhecimento papel relevante no "estar no mundo" da espécie humana. É, fundamentalmente, através do conhecimento lato sensu que o homem se relaciona com a realidade, num processo de apreensão e reação ao real, que pode vir ou não a transformá-lo, através de atitudes mais ou menos conscientes (7).

Dispor de informações e, principalmente, de dados corretos sobre a realidade dá ao homem uma possibilidade maior de interven ção e, também, pode permitir que tal intervenção se dế de modo consciente, não-alienado. 
A qualidade da informação, evidentemente, está na dependência de um conjunto de fatores. Dentre eles, podemos destacar alguns, tais como: o pouco conhecimento de epidemiologia por parte de algumas autoridades, inclusive da própria área de saúde; a pouca compreensão por parte dos jomalistas dos assuntos cobertos e a dificuldade de comunicaçāo entre autoridades ou técnicos e jornalistas, gerando informações parciais ou mesmo distorcidas.

Podemos citar alguns exemplos, a título de ilustração. O redator médico da Folha de São Paulo, em artigo publicado nesse jomal e na Folha da Tarde, em 9 de julho de 1988, por exemplo, afirma a inexistência de vacinas, quando o Estado já havia, inclusive, recebido uma doação de 300 mil doses do governo cubano.

Nos casos detectados atualmente, o responsável tem sido o meningococo tipo $B$, para o qual, até o momento, não se tem notícias da existência de uma vacina...(12).

A apresentação do diagrama de controle para a doença meningocócica, na região metropolitana, e a incidência observada nos seis primeiros meses de 88 vieram acompanhadas de um texto, informando que Acima de 0,25 (casos por 100.000 hab), a curva indica epidemia (13).

Certamente a informação passada por técnicos do CVE ou foi incompleta, ou foi mal compreendida pelo jomalista, uma vez que não há um limite único e fixo, a partir do qual se considere a incidência epidêmica. O limite é constituído pelo próprio diagrama, e os valores máximos do coeficiente variam a cada mês, exatamente porque a incidência não é idêntica, ao longo do ano, apresentando marcada variação sazonal (aumento nos meses de outono e inverno e redução na primavera e verão).

Além disso, os valores considerados como indicativos de incidência habitual (endêmica) ou epidêmica variam de lugar para lugar e nas diferentes épocas, desautorizando comparaçöes entre diferentes populações, em momentos históricos diversos.

A divulgação desse tipo de informaçāo reforça, na população, a visão das doenças como algo natural, desprovido de historicidade, embora não tenha imediatamente maiores conseqüências sobre atitudes pragmáticas com relação à epidemia. Tal não é o caso, quando as informaçōes errôneas se referem, por exemplo, aos mecanismos de transmissão:

A meningite do tipo $B$... representa menor perigo... porque só se dissemina em ambientes fechados... enquanto as do tipo $A$ e $C$ são de transmissão incontrolável pois se propagam através do ar (15). 
Toda a informação contida no trecho acima é incorreta. Todos os meningococos se transmitem apenas por contágio direto entre pessoas. As bactérias são eliminadas nas gotículas de secreção da garganta e precisam atingir a mucosa da garganta de outra pessoa para produzir infecção. Tecnicamente, a transmissão não se faz pelo ar, já que, na ausência de uma pessoa contaminada, não ocorre transmissão. Além disso, os meningococos morrem rapidamente fora do organismo humano.

A diferença entre os vários grupos de meningococos está nas diferentes taxas de infectividade que eles apresentam e não em diferentes modos de transmissão.

A infectividade é a capacidade que a bactéria tem de provocar infecção, e ela parece ser maior para o sorogrupo $\mathrm{A}$ do que para o $\mathrm{C}$ e o $\mathrm{B}$.

$\mathrm{O}$ desconhecimento das características do agente etiológico e de suas formas de transmissão pode levar a comportamentos totalmente ineficazes, desnecessários e até mesmo aterrorizadores, como as adotadas pelo Serviço Funerário:

a superintendência do Serviço Funerário do Municipio de São Paulo determinou: qualquer tipo de óbito, em que conste meningiie, as urnas funerárias deverão ser metálicas, soldadas, $e$ as medidas de segurança adotadas serão as mesmas para as doenças infecto-contagiosas (16).

O próprio assessor de imprensa da Secretaria da Saúde demonstra desconhecimento, ao tentar estabelecer uma distinção entre surto epidêmico e epidemia, baseado na possibilidade ou não de controle em uma situação ou outra.

o órgão opta pelo termo surto epidêmico por ser possível o controle da propagaçāo da meningite tipo $B$ (19).

$\AA$ distinção correta, do ponto de vista epidemiológico, entre surto e epidemia não envolve diretamente a possibilidade ou não de controle. O termo surto costuma ser usado para a ocorrência de doenças transmissíveis em grupos de população relativamente confinados, tais como as crianças de uma creche, trabalhadores de uma fábrica, os recrutas de um quartel e outras situações semelhantes. O termo epidemia é usado para indicar a ocorrência excessiva de casos de doenças transmissíveis em populações abertas, tal como a de uma grande cidade como São Paulo.

Tanto não havia possibilidade de controle da propagação que, um ano depois, a incidência havia dobrado. Mesmo em se tratando de surto, a propagação só terminaria, quando todos os indivíduos expostos tivessem sido infectados ou imunizados. 
Outro fato dificilmente aceito, quer por parte dos jomalistas, quer por parte da população, é a existência de gaps no conhecimento. O fato dos técnicos não saberem tudo sobre a doença coloca sob suspeição aquilo que eles sabem:

Epidemiologistas no Brasil e no exterior não sabem explicar por que a doença aparece. Logo também não sabem como evitá-la... (26).

Na verdade, o que nảo se sabe é como uma epidemia aparece, embora até se saiba, provavelmente, por que aparece. Isto, entretanto, não determina que não se saiba como enfrentá-la. A sensação transmitida pelo artigo em questão é a de que os médicos desconhecem a doença e não sabem bem o que devem fazer.

O que ocorre é que determinar todos os fatores responsáveis pelo surgimento de uma epidemia não é uma tarefa fácil. Entretanto, felizmente, a história da medicina é pródiga em exemplos de atuação eficientes dos órgãos de saúde no combate a muitas doenças e epidemias, mesmo antes de se conhecer adequadamente seu processo de produção.

Algumas vezes, a desinformação é agravada por posiçōes ideológicas, que dificultam a análise correta dos fatos e levam à divulgação de verdadeiros "absurdos". A citação a seguir será bastante longa, mas, também, extremamente ilustrativa:

... mas o secretário da Saúde chega a declarar: $\ddot{E}$ importante que as escolas permaneçam abertas para que possamos acompanhar os casos. A expressão acompanhar os casos significa, neste contexto, usar crianças como cobaias para medir $o$ alcance $e$ a porcentagem de expansão da epidemia...

...Como a vacina, por definição, é preventiva $e$ como as pessoas vacinadas náo irão depois ser propositadamente contagiadas, isso significa que o governo jamais saberá se, sem a vacina, elas iriam ou não contrair a enfermidade $e$, portanto, se o medicamento serve ou não.

Por que tanta prudência em relação à vacina? Será porque nosso Governo, profundamente democrático, não pode permitir que seja usada em nosso território uma vacina produzida em um País comunista?

Parece que não, pois é justamente aqui que se manifesta de forma mais chocante a incongruência governamental. A Ideologia exportada por Cuba e da qual Fidel Castro é uma das últimas espécimes a acreditar $e$, assim mesmo, só para não perder o emprego de ditador, é disseminada sem nenhuma reserva em todas as nossas escolas. Basta ver, a propósito, como é ensinada a História totalmente deformada para se adaptar a dog- 
mas ideológicos nos quais nem Gorbachev acredita mais.

Como não há nenhuma lei que proiba a venda, no território nacional, de uma ideologia cuja eficiência não tenha sido comprovada no país, o governo cruza os braços... (24).

Há nesse extenso trecho algumas informaçōes totalmente erradas. O primeiro parágrafo acusa a secretaria de saúde de não permitir a suspensão das aulas para utilizar as crianças como "cobaias".

Absolutamente a situação não é esta!

A suspensão das aulas não é recomendada por três motivos principais: primeiro, a duração de uma epidemia de meningite meningocócica costuma ser demorada, cerca de cinco a sete anos, logo, não seria adequado manter as crianças fora da escola por tanto tempo; segundo, as condiçōes de aglomeração intradomiciliar para as crianças, na periferia, são mais desfavoráveis do que a freqüência à escola e; terceiro, na escola, as professoras podem detectar as primeiras manifestações da doença, socorrendo as crianças cujas mães se encontram ausentes do domicílio, durante sua jornada de trabalho.

No segundo parágrafo, o autor questiona a possibilidade de se chegar a conhecer a eficácia da vacina. Evidentemente $o$ autor desconhece os procedimentos metodológicos da epidemiologia que permitem, a partir da observação da incidência da doença entre vacinados e não-vacinados, se chegar ao cálculo da eficácia. Obviamente não seria ético submeter as crianças à inoculação da bactéria, apenas para poder demonstrar que a vacina funciona, até porque todas as vacinas apresentam algum grau de fracasso e, neste caso, estaríamos produzindo, deliberadamente, a doença, entre algumas crianças.

$\mathrm{O}$ restante do artigo apenas explicita as posições ideológicas do autor que, contraditoriamente, parece questionar o caráter democrático do estado brasileiro, embora, simultaneamente, proponha maior rigor por parte do governo no que se refere à divulgação de "certas ideologias".

Para garantir o acesso à informação de qualidade à populaçẫo, é necessário, portanto, que as autoridades e técnicos da área de saúde se disponham a assumir uma postura efetivamente democrática, preocupandose com a divulgação dos fatos, mas, também, com a comunicação de informações completas, corretas e fidedignas.

Por outro lado, os órgãos de imprensa devem se preocupar em desempenhar com competência sua tarefa de meios de comunicação de massa, evitando as abordagens sensacionalistas e estimulando a "profissionalização" de seus jornalistas também nos setores

Cadernos de Saúde Pública, RJ, 6 (4): 385-399, out/dez, 1990 
sociais, tal como já vem ocorrendo nos setores de economia e política.

De posse das informações, os vários segmentos sociais serão capazes de avaliar a situação $e$, mais ativamente, atuar na solução de seus próprios problemas.

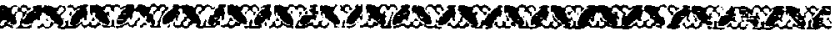

This article discusses the role of the press in the diffusion of health information during an epidemics outbreak. After having analysed the news published at the São Paulo City press since January 1988, we identified some patterns of behavior by health authorities and by the press. The right to information is discussed in relation to the construction of a critical health awareness wich allows social groups to act when facing health situation of potencial threat.

\section{REFERÊNCIAS BIB LIOGRÁFICAS}

1. ALTHUSSER, Louis - Ideologia e aparelhos ideologicos do Estado, Ed. Presença/Martins Fontes, SP, 1980.

2. BARATA, Rita C. Barradas - Meningite: uma doença sob censura?, Ed. Cortez, SP, 1988.

3. CARDOSO, Fernando Henrique - Autoritarismo e Democratização, Ed. Paz e Terra, RJ, 1975.

4. CARDOSO, Fernando Henrique e MARTINS, Carlos Estévan - Polftica e Sociedade, vol. 1, Ed. Nacional, SP, 1979.

5. FERNANDES, Florestan - A revoluçäo burguesa no Brasil, Ed. Zahar, R J, 1976.

6. MARTINS, Carlos Estévan - A tecnocracia na historia, Ed. Alfa-Omega, SP, 1975.

7. PINTO, Álvaro Vieira - Ciência e Existência, Ed. Paz e Terra, RJ, 1979.

8. PORTELLI, Hugues - Gramsci e o bloco histórico, Ed. Paz e Terra, RJ, 1977.

NOTÍCIAS DE JORNAL UTILIZADAS NO ARTIGO

9. Folha de São Paulo - "Dados sobre Meningite prenunciam epidemia, diz Secretário da Saúde", 06/07/88.

10. Folha da Tarde - "Borges da Silveira năo vê motivo para preocupaçāo", 08/07/88.

11. Folha de São Paulo - "Ministério detecta pré-surto de meningite", 08/07/88. 
12. Folha da Tarde - "Autoridades estão abrindo o jogo", Júlio Abramczyki, 09/07/88.

13. Folha de São Paulo - "Diagrama de Controle", 09/07/88.

14. Diário Popular - "Casos de meningite indicam epidemia", $12 / 07 / 88$.

15. Jomal da Tarde - "O tipo B é menos epidêmico. Veja por que", $12 / 07 / 88$.

16. Estado de São Paulo - "Atestados não falam do tipo de meningite", 13/07/88.

17. Diário Popular - "Secretaria já admite epidemia de meningite", 13/07/88.

18. Folha da Tarde - "Ministério confirma surto de meningite", $14 / 07 / 88$.

19. Diário Popular - "Socorro imediato ajuda no combate à meningite", 14/07/88.

20. Folha da Tarde - "Delegado pode interditar templo por causa de meningite", 01/08/88.

21. Folha de São Paulo - "Meningite na grande São Paulo", $03 / 08 / 88$.

22. Jornal da Tarde - "Há vacinas nos Estados Unidos. Mas nåo servem para o Brasil", 06/08/88.

23. Diário Popular - "Ministro nega epidemia de meningite", $10 / 08 / 88$.

24. Folha da Tarde - "A vacina comunista", Lenildo Tabosa Pessoa, 11/08/88.

25. Diário Popular - "Secretaria reconhece que há epidemia de meningite", 23/04/89.

26. Estado de São Paulo - "Ninguém explica a meningite", $06 / 05 / 89$.

27. Folha de São Paulo - "Ministério da Saúde diz que epidemia já atinge 13 capitais", 21/06/89.

28. Estado de São Paulo - "Vacina contra meningite será paga", 22/06/89.

29. Estado de São Paulo - "Espfrito Santo recomenda patuás contra meningite", 23/06/89. 